\title{
Dimensional Analysis of Gas Holdup of Venturi Carbonation Reactor for Red Mud Processing
}

\author{
Yibin Xiao, ${ }^{1}$ Yan Liu $\left(\mathbb{D},{ }^{1}\right.$ Zhibin Zhao, ${ }^{2}$ Ting'an Zhang, ${ }^{1}$ and Ruibing Li $\mathbb{D}^{3}$ \\ ${ }^{1}$ School of Metallurgy, Northeastern University, Shenyang 110819, China \\ ${ }^{2}$ Shenyang Aluminium and Magnesium Engineering and Research Institute (SAMI), Shenyang 110001, China \\ ${ }^{3}$ School of Mechanical and Power Engineering, Shenyang University of Chemical Technology, Shenyang 110142, China
}

Correspondence should be addressed to Ruibing Li; lrb07@163.com

Received 17 December 2019; Revised 25 February 2020; Accepted 2 April 2020; Published 30 June 2020

Academic Editor: Yannis Dimakopoulos

Copyright (C) 2020 Yibin Xiao et al. This is an open access article distributed under the Creative Commons Attribution License, which permits unrestricted use, distribution, and reproduction in any medium, provided the original work is properly cited.

Gas holdup is an important parameter in the carbonation reaction for processing red mud. In this paper, for estimating the gas holdup of Venturi carbonation reactor, water model experiments were performed. The effects of superficial gas velocities, superficial liquid velocities, and liquid-to-solid and height-to-diameter ratio on the gas holdup are investigated. Through dimensional analysis using Buckingham $\pi$ principle, a derivation of the empirical correlation is also proposed. The results indicate that gas holdup increases with the increase in gas velocity, with the decrease in liquid velocity, with the increase in liquid-to-solid ratio, and with the increase in height-to-diameter ratio. The calculated results from the empirical correlation agree well with the experimental data, which is important for designing a highly efficient Venturi reactor with a high temperature, high pressure, and three phases of gas, liquid, and solid.

\section{Introduction}

Red mud is a solid residue, which is generated during alumina extraction from bauxite. According to the properties of bauxite and alumina production conditions, $0.6-2.5$ tons of residue were generated for every ton of $\mathrm{Al}_{2} \mathrm{O}_{3}$ during alumina production [1]. Approximately 120 million tons of Bayer red mud were generated every year worldwide, and substantial reserves of over 2.7 billion tons have accumulated [2]. Every alumina plant allocates a large yard for stacking the Bayer red mud. The industrial solid waste encroaches a great amount of land, causes air pollution, contaminates soil or groundwater, and results in serious environmental problems because of the tiny particles and alkaline slurry. The utilization and recycling of red mud is currently a critical issue and needs to be addressed as soon as possible.

Researchers have made significant efforts to explore the utilization of red mud in aluminum industry. Some of them involve the extraction of valuable materials from red mud, such as the recovery of alumina, soda, ferric oxide, and titanium oxide [3-5]. Most of the red mud is still stacked in yard, although a significant amount of red mud is utilized as subgrade materials $[6,7]$ and additive for cement $[8]$ and ceramics [9], and for various other industrial uses [10, 11]. The biggest hurdle in the use of red mud is the composition of soda in red mud slurry. Soda needs to be removed prior to utilizing the red mud in industrial processes.

Although many processes have been proposed for the utilization of red mud, only a few have been applied in industrial processes due to unfavorable local economic and market conditions. It is worth mentioning that most of these processes suffer from high costs and low yields. For fully using the Bayer process residue, the team of Northeastern University, China, proposed a novel approach, called the calcification-carbonation method $[12,13]$. The method mainly involves two steps of calcification and carbonation. In the first step of calcification, lime is added to red mud slurry in an autoclave at the temperature of $180-240^{\circ} \mathrm{C}$, whereas the calcification reaction occurs in the solution, during which the silicon phase is transformed into hydrogarnet $\left(3 \mathrm{CaO} \cdot \mathrm{Al}_{2} \mathrm{O}_{3} \cdot x \mathrm{SiO}_{2} \cdot(6-2 x) \mathrm{H}_{2} \mathrm{O}\right)$. As a result, soda in red mud is extracted: 


$$
\begin{aligned}
\frac{x}{2}\left(\mathrm{Al}_{2} \mathrm{O}_{3} \cdot 2 \mathrm{SiO}_{2} \cdot 2 \mathrm{H}_{2} \mathrm{O}\right)+3 \mathrm{Ca}(\mathrm{OH})_{2}+(2-x) \mathrm{Al}(\mathrm{OH})_{3} \\
=3 \mathrm{CaO} \cdot \mathrm{Al}_{2} \mathrm{O}_{3} \cdot x \mathrm{SiO}_{2}(6-2 x) \mathrm{H}_{2} \mathrm{O}+\frac{3 x}{2} \mathrm{H}_{2} \mathrm{O} \\
\quad \mathrm{Na}_{2} \mathrm{O} \cdot \mathrm{Al}_{2} \mathrm{O}_{3} \cdot x \mathrm{SiO}_{2}(6-2 x) \mathrm{H}_{2} \mathrm{O}+3 \mathrm{Ca}(\mathrm{OH})_{2} \\
=3 \mathrm{CaO} \cdot \mathrm{Al}_{2} \mathrm{O}_{3} \cdot x \mathrm{SiO}_{2}(6-2 x) \mathrm{H}_{2} \mathrm{O}+2 \mathrm{NaOH}+2 \mathrm{H}_{2} \mathrm{O}
\end{aligned}
$$

In the second step of carbonation, carbon dioxide $\left(\mathrm{CO}_{2}\right)$ is bubbled into the calcified red mud slurry in the carbonation reactor at $80-120^{\circ} \mathrm{C}$ under a $\mathrm{CO}_{2}$ partial pressure of 0.5-1.2 MPa. The hydrogarnet is decomposed into calcium silicate, calcium carbonate, and aluminum hydroxide, whereas alumina is recovered during the process.

Based on this method, $49 \%$ of alumina and $96.8 \%$ of soda are extracted from red mud. The new-phase red mud, which mainly consists of calcium carbonate, calcium silicate, and trace amounts of $\mathrm{Na}_{2} \mathrm{O}$, is obtained. The new-phase red mud satisfies the requirements for the production of Portland cement and, therefore, can be used fully.

The main unit operation for the process is the carbonation reactor. A Venturi carbonation reactor was adopted for the carbonation reaction, which is a type of self-stirring reactor with a cylindrical vertical cross section and a conical bottom equipped with a Venturi tube (Figure 1). The carbonation reaction is a three-phase reaction consisting of gas, liquid, and solid. The ascending $\mathrm{CO}_{2}$ gas, which is laterally introduced near the bottom, disperses into the red mud slurry within the reactor. The carbonation reaction is performed during the rising of gas and slurry. The efficiency of the carbonation reaction is governed by the concentration of gas in liquid and the contact surface of bubbles with solid. Generally speaking, in gas-liquid-solid flow systems, this contact mainly depends on several factors, including the bubble sizes and their distributions [14, 15], gas holdup $[16,17]$, and bubble rise velocity $[18,19]$.

Gas holdup $(\varepsilon)$ is an important parameter in hydrodynamics, which is widely used to determine the characteristics of gas-liquid-solid phase in fluidized beds and bubble columns $[20,21]$. The gas holdup is the volume fraction of gas in the reactor, indicating the size of the contact area of gas with liquid. The gas holdup significantly affects the efficiencies of mass transfer, heat transfer, and microrate of reaction. The gas holdup distribution is mainly related to the superficial gas velocity, solids' concentration, pressure distribution, density of each phase, and the physical properties of the liquid [22].

This is particularly important for the reactor proposed in this study, where the gas holdup characteristics are not yet clear, especially at a quantitative level. Various measuring techniques, such as pressure difference techniques [23, 24], high-speed camera [25], double optical probe [26, 27], particle image velocimetry (PIV) technology [28, 29], and tomography techniques $[30,31]$, have been proposed to study the hydrodynamic behaviors of gas-liquid flows. Numerical modeling and simulations were proposed to

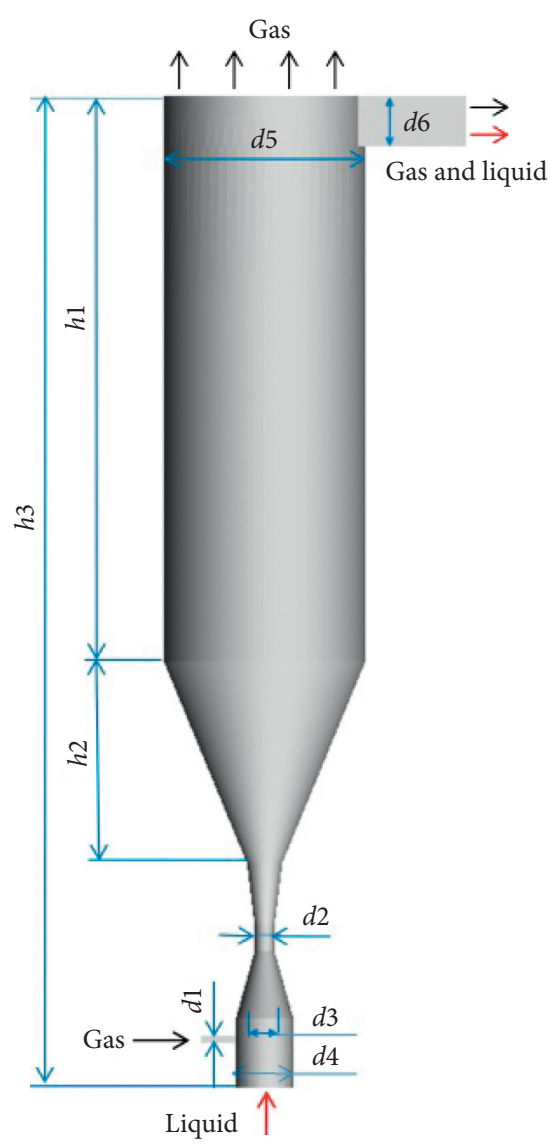

FIgURE 1: Venturi carbonation reactor.

predict the distribution of a radial gas holdup, global gas holdup, and the two-phase flow field [32-34]. These techniques provide useful information to better understand the gas-liquid flows under different conditions. However, these techniques may have certain limitations. For example, the measurement of gas holdup in the transient flow, which is related to fluid velocities, dimensions of the equipment, and the properties of the fluid, is generally difficult and, in many cases, involves high costs. However, such detailed information is highly desirable for the present new reactor.

In this paper, based on the water model experiments for the Venturi carbonation reactor, the gas holdup and the relationship between the gas holdup and various parameters in the carbonation process are studied, and an empirical correlation is derived for gas holdup as a function of superficial gas velocities, superficial liquid velocities, and liquid-to-solid and height-to-diameter ratio. The applicability of the correlation is validated, following which, the effects of various parameters on the gas holdup of the Venturi carbonation reactor can be quantified that benefits the performance of the novel reactor.

\section{Experimental}

2.1. Principles. For the simulation of carbonation reactor, the geometric and dynamic similarities are necessary. A water model with geometric similarity, in which the main 
geometrical sizes are proportional to the prototype on a scale of $1: 6$ is established. Meanwhile, the dynamic similarity follows the rule that the modified Froud numbers (Fr) for the model and prototype are equal. The modified Froud number is defined using

$$
\operatorname{Fr}^{\prime}=\frac{\rho_{g} \cdot u^{2}}{\rho_{l} \cdot g \cdot H},
$$

where $u$ is the characteristic velocity $(\mathrm{m} / \mathrm{s}), H$ is the depth of pool $(\mathrm{m}), \rho_{l}$ and $\rho_{g}$ are the densities of liquid and gas $\left(\mathrm{kg} / \mathrm{m}^{3}\right)$, respectively, and $g$ is the acceleration due to gravity $\left(\mathrm{m} / \mathrm{s}^{2}\right)$.

The characteristic velocity can be expressed using

$$
u=\frac{4 Q}{\pi \cdot d^{2}}
$$

where $Q$ is the flow rate of fluid $\left(\mathrm{m}^{3} / \mathrm{h}\right), d$ is the throat diameter of the jet reactor $(\mathrm{m})$, and $\pi$ is the circular constant. Combining equations (2) and (3), the modified Froud number is obtained, which is given by

$$
\mathrm{Fr}^{\prime}=\frac{1.621 \rho_{g} \cdot Q^{2}}{\rho_{l} \cdot g \cdot H \cdot d^{4}}
$$

From $\mathrm{Fr}_{m}^{\prime}=\mathrm{Fr}_{p}^{\prime}$, the quantity of fluid injected into the model can be calculated:

$$
Q_{m}=\left(\frac{\rho_{g p}}{\rho_{g m}} \cdot \frac{\rho_{l m}}{\rho_{l p}} \cdot \frac{d_{m}^{4}}{d_{p}^{4}} \cdot \frac{H_{m}}{H_{p}}\right)^{1 / 2} \cdot Q_{p},
$$

where the subscripts $p, m, l$, and $g$ stand for prototype, model, liquid, and gas, respectively.

2.2. Apparatus. The water model used in the experiment refers to the design for industrial implementation of red mud process, which includes a main reactor, a fluid circulation system, and an observation system. The newly designed Venturi jet flow device used for the calcified slag carbonation is a prototype, in which the Venturi tube is used as a liquid entry point at the bottom. This part helps in generating a negative pressure relative to the ambient atmospheric pressure, which sucks gas into the reactor through gas inlet. The gas mainly escapes from the outlet at the top, whereas liquid and bubbles are removed from the right side of the outlet (Figure 1). The geometrical parameters for the reactor are listed in Table 1.

In the water model system, materials made up of organic glass were used to ensure a steady movement of the fluid and observe the mixing of fluid, circulation stream, and bubble behavior (Figure 2). The size and the distribution of gas bubbles and their movements were directly observable.

2.3. Methodology. The pressure-difference method was used to measure the gas holdup in the reactor. According to Bernoulli principle, the pressure difference between the two cross sections of fluidized bed in the reactor was measured. For the gas-liquid system, the density of the mixture of gas and liquid is given by
Table 1: Geometric parameters of the Venturi Carbonation reactor.

\begin{tabular}{lcc}
\hline Parameters & Symbol & $\begin{array}{c}\text { Value } \\
(\mathrm{mm})\end{array}$ \\
\hline $\begin{array}{l}\text { Length of cylindrical section } \\
\text { Length of spread section }\end{array}$ & $h_{1}$ & 675 \\
Length of carbonation reactor & $h_{2}$ & 240 \\
Diameter of the gas inlet & $h_{3}$ & 1183 \\
Diameter of throat of the carbonation & $d_{1}$ & 10 \\
reactor & $d_{2}$ & 30 \\
Diameter of the throat of liquid inlet & $d_{3}$ & 14.7 \\
Diameter of the liquid inlet & $d_{4}$ & 42 \\
Diameter of the cylindrical section & $d_{5}$ & 240 \\
Diameter of the liquid outlet & $d_{6}$ & 100 \\
\hline
\end{tabular}

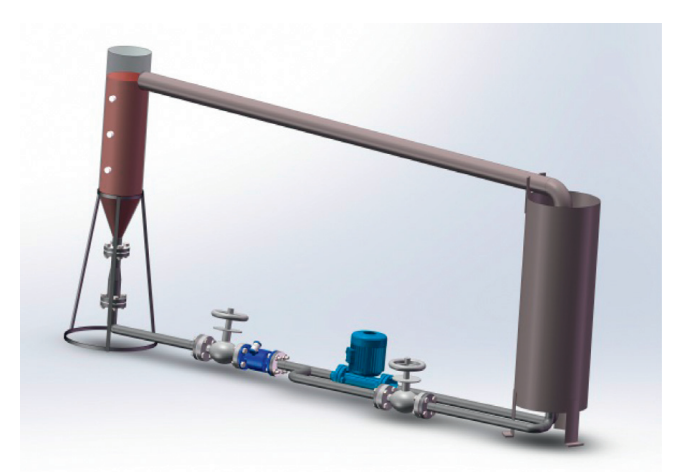

Figure 2: Water model system.

$$
\rho_{\text {mix }}=\rho_{g} \varepsilon_{g}+\rho_{l}\left(1-\varepsilon_{g}\right) \text {. }
$$

The pressure difference between the two cross sections is given by

$$
P=\rho_{\text {mix }} g h .
$$

The gas density $\rho_{g}$ is very small as compared to the liquid density $\rho_{l}$ and, therefore, can be ignored. From equations (6) and (7), the gas holdup can be calculated using

$$
\varepsilon_{g}=1-\frac{P}{\rho_{l} g h},
$$

where $\varepsilon_{g}$ is the gas holdup, $g$ is the acceleration due to gravity $\left(\mathrm{m} / \mathrm{s}^{2}\right), \rho_{\text {mix }}$ is the density of gas-liquid mixture in the reactor $\left(\mathrm{kg} / \mathrm{m}^{3}\right), \rho_{l}$ is the density of liquid in the reactor $\left(\mathrm{kg} / \mathrm{m}^{3}\right), h$ is the altitude difference between the two measuring sections of a fluidized bed in a reactor $(\mathrm{m})$, and $P$ is the pressure difference between the two cross sections $(\mathrm{kPa})$.

2.4. Dimensional Analysis. Dimensional analysis is a method for reducing complex physical problems to their simplest form by studying the dimensions of variables that describe the physical phenomenon. The principal use of dimensional analysis is to make the physical equation dimensionally homogeneous. The method is of great generality and mathematical simplicity. In engineering, empirical correlation among various parameters can be derived from experimental data using the method of dimensional analysis, which also enables weighing the magnitude of each operating parameter. 


\section{Dimensional Analysis of Gas Holdup}

Based upon the water model experiments, the gas holdup $\left(\varepsilon_{g}\right)$ in the reactor is mainly related to superficial gas velocity $\left(U_{q}\right)$, superficial liquid velocity $\left(U_{l}\right)$, liquid-tosolid ratio $\left(R_{\mathrm{ls}}\right)$, and height-to-diameter ratio $\left(R_{\mathrm{hd}}\right)$ [23]. Based on the dimensional analysis, the influence of various factors on the gas holdup in the reactor is studied. According to Buckingham's theorem ( $\pi$ principle), a general functional form of the independent variables was obtained and is given in the following equations [35-37]:

$$
\varepsilon_{g}=f\left(U_{g}, U_{l}, R_{\mathrm{ls}}, R_{\mathrm{hd}}, d_{1}, d_{2}, d_{5}, H, \mu_{g}, \rho_{g}, \mu_{l}, \rho_{l}\right),
$$

or

$$
f\left(\varepsilon_{g}, U_{g}, U_{l}, R_{\mathrm{ls}}, R_{\mathrm{hd}}, d_{1}, d_{2}, d_{5}, H, \mu_{g}, \rho_{g}, \mu_{l}, \rho_{l}\right)=0,
$$

where $\varepsilon_{g}$ is the gas holdup, $U_{g}$ and $U_{l}$ are the superficial velocities of gas and liquid $(\mathrm{m} / \mathrm{s})$, respectively, $R_{\mathrm{ls}}$ is the liquid-to-solid ratio, $R_{\mathrm{hd}}$ is the height-to-diameter ratio, and $d_{1}, d_{2}$, and $d_{5}$ are the diameter of gas inlet of the jet reactor $(\mathrm{m})$, diameter of the throat of the jet reactor $(\mathrm{m})$, and diameter of the reactor $(\mathrm{m})$, respectively. Furthermore, $H$ is the height of liquid level in the reactor $(\mathrm{m}), \mu_{g}$ and $\mu_{l}$ are the viscosities of gas and liquid (Pa.s), respectively, and $\rho_{g}$ and $\rho_{l}$ are the densities of gas and liquid $\left(\mathrm{kg} / \mathrm{m}^{3}\right)$, respectively. The dimensions of the variables are listed in Table 2.

Based on $\pi$-principle, the total number of variables $(n)$ is 13 and the number of independent variables $(k)$ is 5 , so that $n-k=8$, which is the number of dimensionless quantities that can be set up. Furthermore, $\rho_{g}, \mu_{g}, \rho_{b}, \mu_{l}$, and $d_{5}$ were selected as the independent variables, whereas $\varepsilon_{g}, R_{\mathrm{ls}}$, and $R_{\text {hd }}$ were selected as the dimensionless values. Then, according to the $\pi$-principle, the dimensionless forms of the remaining $n-k$ independent variables were defined as follows [35-37]:

$$
\begin{aligned}
& \Pi_{0}=\varepsilon_{g}, \\
& \Pi_{1}=R_{\mathrm{ls}}, \\
& \Pi_{2}=R_{\mathrm{hd}}, \\
& \Pi_{3}=\frac{U_{g} \rho_{g} d_{1}}{\mu_{g}}, \\
& \Pi_{4}=\frac{U_{l} \rho_{l} d_{2}}{\mu_{l}}, \\
& \Pi_{5}=\frac{d_{1}}{d_{5}}, \\
& \Pi_{6}=\frac{d_{2}}{d_{5}},
\end{aligned}
$$

TABLE 2: Dimensions of the variables.

\begin{tabular}{cccccccccccccc}
\hline & $\varepsilon_{g}$ & $U_{g}$ & $U_{l}$ & $R_{\mathrm{ls}}$ & $R_{\mathrm{hd}}$ & $d_{1}$ & $d_{2}$ & $d_{5}$ & $H$ & $\rho_{g}$ & $\mu_{g}$ & $\rho_{l}$ & $\mu_{l}$ \\
\hline$M$ & 0 & 0 & 0 & 0 & 0 & 0 & 0 & 0 & 0 & 1 & 1 & 1 & 1 \\
$L$ & 0 & 1 & 1 & 0 & 0 & 1 & 1 & 1 & 1 & -3 & -1 & -3 & -1 \\
$T$ & 0 & -1 & -1 & 0 & 0 & 0 & 0 & 0 & 0 & 0 & -1 & 0 & -1 \\
\hline
\end{tabular}

$$
\Pi_{7}=\frac{H}{d_{5}} .
$$

This way, a dimensionless functional form is obtained as follows:

$$
f\left(\varepsilon_{g}, R_{\mathrm{ls}}, R_{\mathrm{hd}}, \frac{U_{g} \rho_{g} d_{1}}{\mu_{g}}, \frac{U_{l} \rho_{l} d_{2}}{\mu_{l}}, \frac{d_{1}}{d_{5}}, \frac{d_{2}}{d_{5}}, \frac{H}{d_{5}}\right)=0 .
$$

An explicit functional form is given by

$$
\varepsilon_{g}=f\left(R_{\mathrm{ls}}, R_{\mathrm{hd}}, \frac{U_{g} \rho_{g} d_{1}}{\mu_{g}}, \frac{U_{l} \rho_{l} d_{2}}{\mu_{l}}, \frac{d_{1}}{d_{5}}, \frac{d_{2}}{d_{5}}, \frac{H}{d_{5}}\right) \text {. }
$$

In addition, $d_{1}, d_{2}$, and $H$ are quantitative in nature. Therefore, equation (20) can be expressed as

$$
\varepsilon_{g}=f\left(R_{\mathrm{ls}}, R_{\mathrm{hd}}, \frac{U_{g} \rho_{g} d_{1}}{\mu_{g}}, \frac{U_{l} \rho_{l} d_{2}}{\mu_{l}}\right) .
$$

\section{Derivation of the Empirical Correlation}

Generally, the criterion equation can be expressed in the form of power function with the independent variable being under certain conditions. Therefore, equation (21) can be rewritten as

$$
\varepsilon_{g}=a_{0} R_{\mathrm{ls}}^{a_{1}} R_{\mathrm{hd}}^{a_{2}}\left(\frac{U_{g} \rho_{g} d_{1}}{\mu_{g}}\right)^{a_{3}}\left(\frac{U_{l} \rho_{l} d_{2}}{\mu_{l}}\right)^{a_{4}},
$$

where $a_{0}, a_{1}, a_{2}, a_{3}$, and $a_{4}$ are the fitting coefficients. After taking the logarithm on both sides of equations (22), equation (23) is obtained:

$$
\begin{aligned}
\ln \varepsilon_{g}= & \ln a_{0}+a_{1} \ln R_{\mathrm{ls}}+a_{2} \ln R_{\mathrm{hd}}+a_{3} \ln \frac{U_{g} \rho_{g} d_{1}}{\mu_{g}} \\
& +a_{4} \ln \frac{U_{l} \rho_{l} d_{2}}{\mu_{l}} .
\end{aligned}
$$

Based on the linear relationship of equation (23), the fitting coefficients $a_{1}, a_{2}, a_{3}$, and $a_{4}$ are obtained by plotting the experimental data in Origin 8.6 (See Figure S1 in the Supplementary Material), whereas $a_{0}$ is optimized using the Quasi-Newton method:

$$
\begin{aligned}
& a_{0}=1.41 \times 10^{-5}, \\
& a_{1}=0.270, \\
& a_{2}=1.185, \\
& a_{3}=0.998, \\
& a_{4}=-0.266 .
\end{aligned}
$$


The values of the coefficients are the mean values of the slopes in their respective graphs. The fitting equation can be expressed using

$$
\varepsilon_{g}=1.41 \times 10^{-5} R_{\mathrm{ls}}^{0.270} R_{\mathrm{hd}}^{1.185}\left(\frac{U_{g} \rho_{g} d_{1}}{\mu_{g}}\right)^{0.998}\left(\frac{U_{l} \rho_{l} d_{2}}{\mu_{l}}\right)^{-0.266} .
$$

The results obtained using equation (25) are consistent with the experimental results. The mean statistical variance is 0.97 (See Table S2 in the Supplementary Material), while the mean relative error is within $8.7 \%$ (See Table S3 in the Supplementary Material). Furthermore, equation (25) is valid within a range of the following parameters: $U_{g}$ of $7.08-21.23 \mathrm{~m} \cdot \mathrm{s}^{-1} ; U_{l}$ of $0.89-1.77 \mathrm{~m} \cdot \mathrm{s}^{-1} ; R_{\mathrm{ls}}$ of $10-20 ; R_{\mathrm{hd}}$ of $3-5$. Figure 3 shows that the calculated results obtained from the fitting equation agree well with the experiment data. Equation (25) is significant for designing a highly efficient Venturi reactor involving high temperature, high pressure, and three phases of gas, liquid, and solid.

\section{Discussion}

5.1. Compatibility of the Similarity Criteria. The establishment of the criteria model is very simple. However, the absence of the physical analysis leads to incorrect results [38]. In this study, thirteen physical quantities involved with the gas holdup were analyzed (equation (9)). These quantities are the determinants, which significantly affect the size, amount, and residence time of gas bubbles in the fluid. Some physical quantities involved with the gas holdup include temperature and surface tension. These parameters are relatively stable in fluid flow and do not have a considerable effect on the gas holdup and, therefore, are not included in the model. In fact, the densities of gas and liquid $\left(\rho_{g}\right.$ and $\left.\rho_{l}\right)$ and viscosities of gas and liquid $\left(\mu_{g}\right.$ and $\left.\mu_{l}\right)$ are stable. Their dimensions can be used to make dimensionless complexes according to $\pi$-theorem which requires that both sides of the physical equation must be dimensionally homogeneous. Eight dimensionless complexes were made (see equations (11)-(18)), wherein $\Pi_{3}$ and $\Pi_{4}$ represent the Reynolds numbers, which often appear in the analysis of heat and mass transfer in fluid flow:

$$
\begin{aligned}
& \operatorname{Re}_{1}=\frac{U_{g} \rho_{g} d_{1}}{\mu_{g}}, \\
& \operatorname{Re}_{2}=\frac{U_{l} \rho_{l} d_{2}}{\mu_{l}} .
\end{aligned}
$$

The Reynolds numbers are the main similarity criteria characterizing the similarities of inertia force and viscosity force in fluid flow. $\Pi_{2}, \Pi_{5}$, and $\Pi_{6}$ characterize the geometric similarities of apparatus, and $\Pi_{0}, \Pi_{1}$, and $\Pi_{7}$ assure the similarities of magnitude of gas, solid, and liquid. The criterion model for estimating the gas holdup of the jet reactor is constructed in the case of a serious physical analysis and understanding of its physical background. Incompatible similarity criteria are not found in the dimensionless complexes. Therefore, it is available in the process of multiphase flow.

The data used in the dimensional analysis was obtained from water model experiments, which were based on the geometric and dynamic similarities. Froude number was used as the dynamic similarity criteria to construct the water model. Using the throat diameter of the jet reactor as a length scale, the Froude number characterizes the similarities of inertia force and gravity in fluid, which assure the dynamic similarity of the water model with the prototype (see Section 2.1).

Figure 4 shows a comparison of the results of the proposed correlation with those of the water experiments. It can be seen that the calculated results are in good agreement with the experimental results. Therefore, the proposed correlation can be used for predicting the gas holdup in the novel reactor.

5.2. Effect of Various Parameters on Gas Holdup. The water model experiments showed that the gas holdup in the Venturi reactor is mainly affected by the superficial gas velocity, superficial liquid velocity, liquid-to-solid ratio $\left(R_{\mathrm{ls}}\right)$, and height-to-diameter ratio $\left(R_{\mathrm{hd}}\right)$. Among them, the superficial gas velocity showed an obvious impact on gas holdup. As shown in Figure 3(a), when $R_{\mathrm{ls}}=20, R_{\mathrm{hd}}=4$, and $U_{l}=1.33 \mathrm{~m} \cdot \mathrm{s}^{-1}$, gas holdup increased with the increase in superficial gas velocity. Notably, the increase in gas velocity increased the number of gas bubbles. With the increase in the superficial gas velocity, the strength of stirring also intensified. Larger gas bubbles were disintegrated into smaller bubbles, whereas the rising velocity of small gas bubbles became slower, due to which, the gas holdup increased.

The superficial liquid velocities showed a weaker effect on gas holdup. With the increase in the superficial liquid velocity, the gas holdup decreased (Figure 3(b)). Fan et al. [39] reported that the bubble rise velocity $\left(U_{q}\right)$ can be expressed in terms of a bubble slip velocity $\left(U_{s}\right)$ and the linear liquid velocity $\left(U_{l}\right)$ using

$$
\frac{U_{g}}{\varepsilon_{g}}=U_{s}+\frac{U_{l}}{\varepsilon_{l}} .
$$

Equation (27) shows that the gas holdup has an inverse relationship with the liquid velocity. In air-water systems, the slip velocity is the major contributor to bubble rise velocity $\left(U_{g} / \varepsilon_{g}\right)$ [39]. However, the bubble rise velocity increases with the increase in liquid velocity, which decreases the gas holdup.

When solid particles are added in the solution, the properties of liquid, such as viscosity, change. The existence of solid particles and the increase in viscosity prevented the disintegration of large bubbles into small bubbles and increased the coalescence of smaller bubbles into larger ones. Furthermore, the residence time of bubbles in the solution decreased. The increase in liquid-to-solid ratio means that the solid particles decreased, due to which the gas holdup increased (Figure 3(c)). 


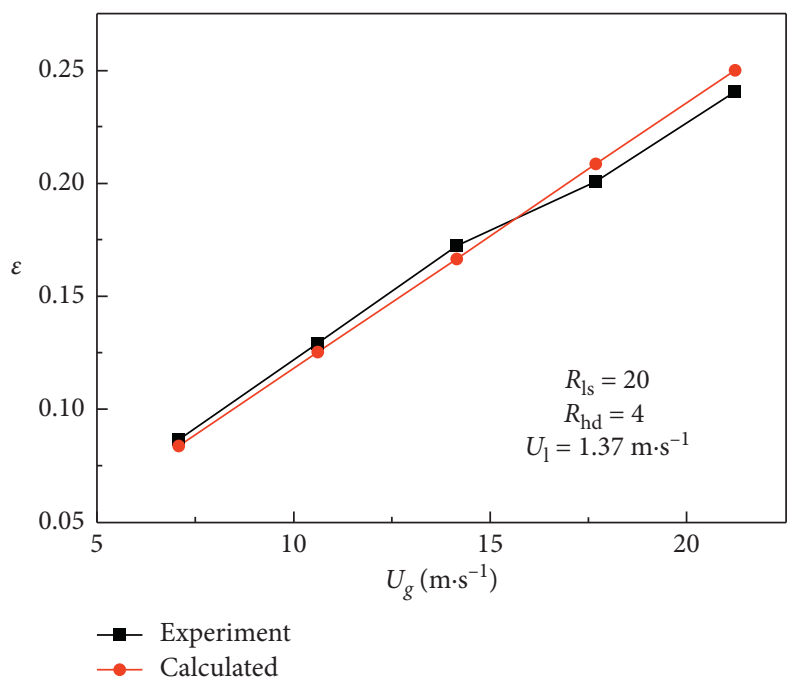

(a)

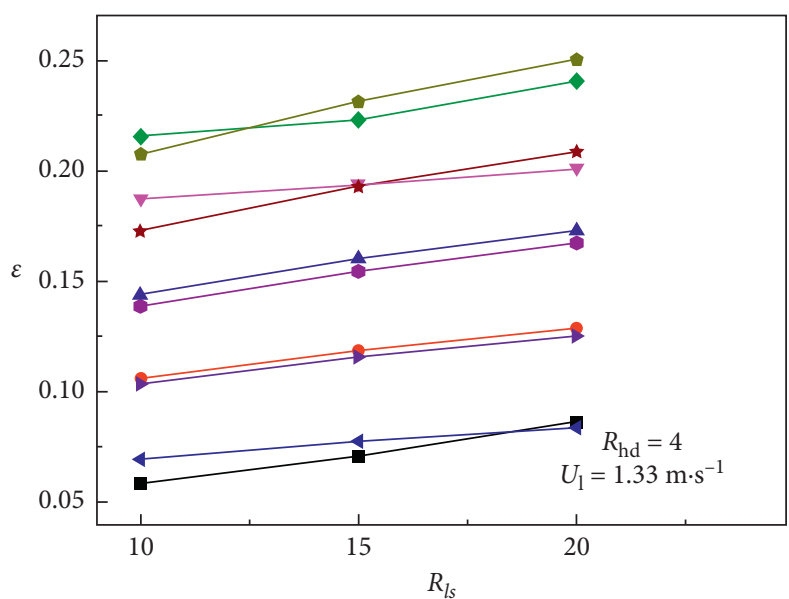

$$
\begin{aligned}
& \text { Experiment: }\left(\mathrm{m} \cdot \mathrm{s}^{-1}\right) \quad \text { Calculated: }\left(\mathrm{m} \cdot \mathrm{s}^{-1}\right) \\
& \text { - } U_{g}=7.07 \\
& \longrightarrow U_{g}=10.62 \\
& \neg U_{g}=14.15 \\
& \checkmark \quad U_{g}=17.69 \\
& \multimap-U_{g}=21.23 \\
& \longleftarrow U_{g}=7.07 \\
& \rightarrow \quad U_{g}=10.62 \\
& \rightarrow U_{g}=14.15 \\
& \star \quad U_{g}=17.69 \\
& \rightarrow U_{g}=21.23
\end{aligned}
$$

(c)

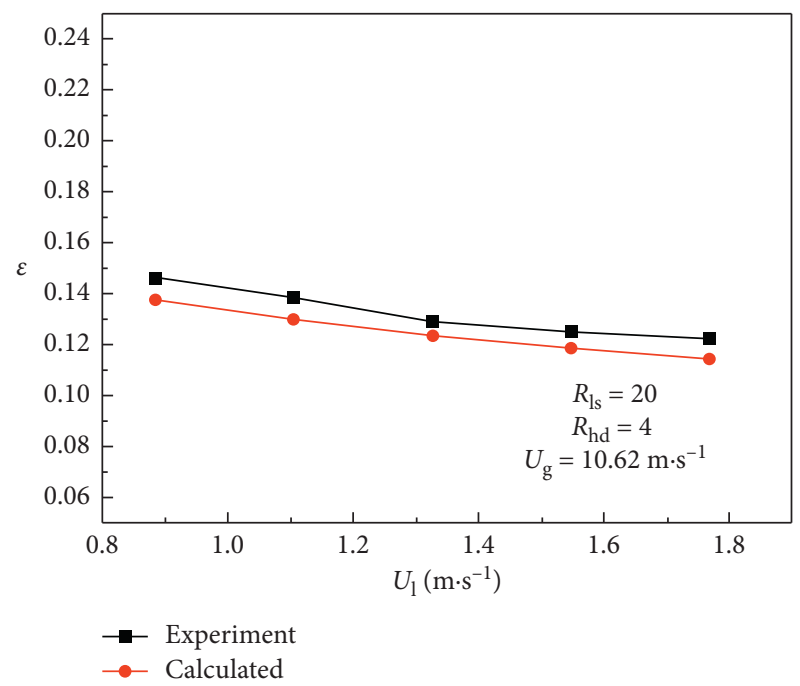

(b)

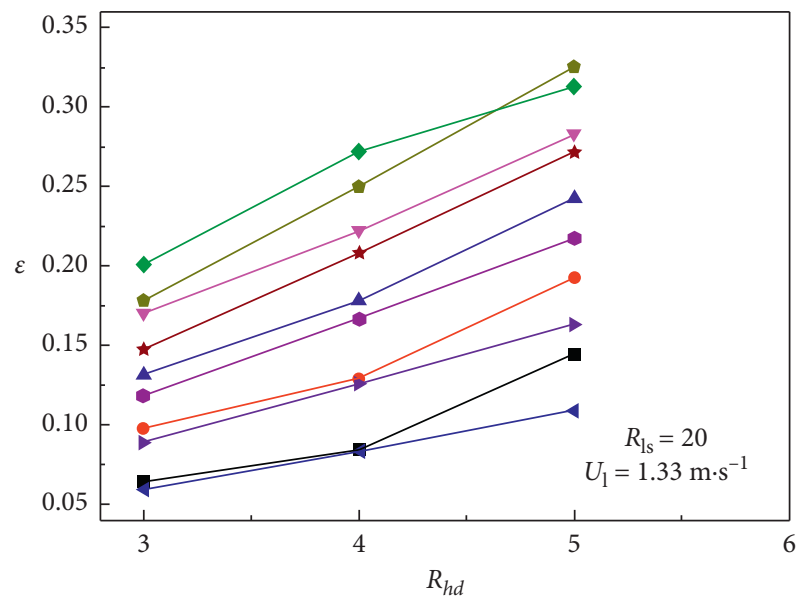

$$
\begin{aligned}
& \text { Experiment: }\left(\mathrm{m} \cdot \mathrm{s}^{-1}\right) \\
& \rightarrow-U_{g}=7.07 \\
& \rightarrow U_{g}=10.62 \\
& \neg U_{g}=14.15 \\
& \rightarrow-U_{g}=17.69 \\
& \rightarrow-U_{g}=21.23
\end{aligned}
$$

Calculated: $\left(\mathrm{m} \cdot \mathrm{s}^{-1}\right)$

$\multimap U_{g}=7.07$

$\rightarrow U_{g}=10.62$

$\rightarrow-U_{g}=14.15$

$\star \quad U_{g}=17.69$

$\rightarrow-U_{g}=21.23$

(d)

Figure 3: Comparison between the experimental and calculated results: (a) $\varepsilon_{g} v s . U_{g}$; (b) $\varepsilon_{g} v s . U_{l}$; (c) $\varepsilon_{g} v s . R_{\mathrm{ls}}$; (d) $\varepsilon_{g} v s . R_{\mathrm{hd}}$.

The ratio of the height to diameter of the reactor $\left(R_{\mathrm{hd}}\right)$ is an important parameter for the equipment. The experimental conditions were set to be as follows: $R_{\mathrm{hd}}=3,4$, and 5, $U_{l}=1.33 \mathrm{~m} \cdot \mathrm{s}^{-1}$, and $R_{\mathrm{ls}}=20$. As shown in Figure 3(d), for low superficial gas velocity and high height-to-diameter ratio, the results show a significant difference between the calculated and experimental values. However, with the increase in the value of $R_{\text {hd }}$, the gas holdup increased.

The increase in temperature led to an expansion of the volume of bubbles, due to which the gas density decreased. According to eqaution (6), the decreased gas density is negligible as compared to the liquid density. This change was taken into consideration in the dynamic similarity, where the flow rate of the gas and gas density were included in the model (equation (4)). Therefore, the gas density and liquid density in equation (25) should be considered when designing industrial unit operations. Similarly, the viscosity of red mud slurry is affected by temperature and is also considered in the model.

The surface tension of bubbles may affect the gas holdup in fluid. Liu et al. [40] discussed the applicability of water experimental results to the hot metal ladle in plant and reported that the differences in the surface tension in molten iron were 3.5 times that of water. Mach [41] reported that the surface tension had a significant effect on gas holdup and hydrodynamics in a three-phase fluidized bed, while viscosity had only a slight impact. Lower liquid surface tension facilitates the formation of smaller bubbles and promotes a noncoalescing tendency in the rising gas bubbles, thus reducing the growth of bubbles. Surfactants can increase drag 


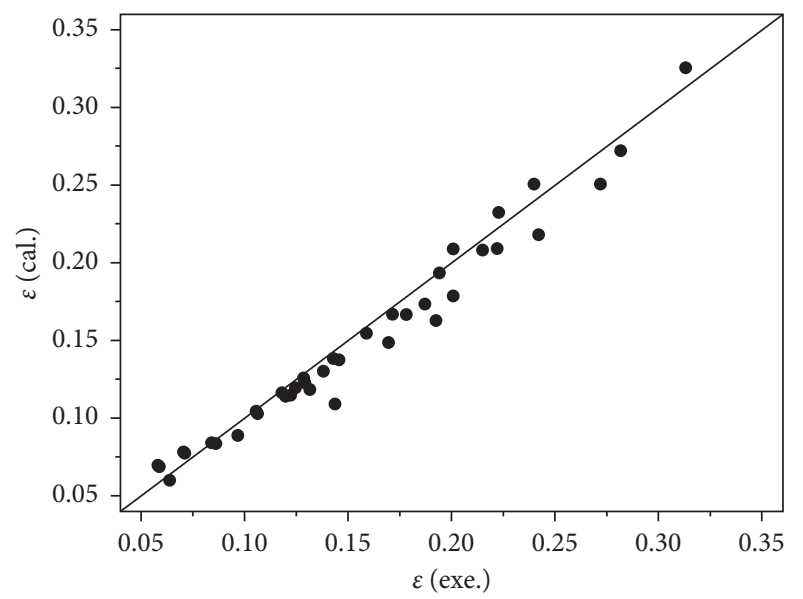

Figure 4: Comparison between the experimental and calculated results.

on gas bubbles due to the formation of a surface tension gradient on the bubble surface [39]. A higher drag results in lower bubble rise velocities, which in turn results in a higher gas holdup.

\section{Conclusions}

Based upon water model experiments, the effects of superficial gas velocities, superficial liquid velocities, and liquid-to-solid and height-to-diameter ratios on gas holdup of the Venturi carbonation reactor were studied. Based upon dimensional analysis and Buckingham's theorem, an empirical correlation was proposed.

Superficial gas velocity is primarily the major influencing factor for gas holdup of the Venturi carbonation reactor. With the increase in superficial gas velocity, the bubbles in the solution and gas holdup increased. The superficial liquid velocity and the values of $R_{\mathrm{ls}}$ and $R_{\text {hd }}$ significantly impacted the gas holdup in the reactor. There is a negative correlation between the superficial liquid velocity and gas holdup of the reactor.

The results obtained using the empirical correlation are consistent with the experimental results and produce a statistical variance of 0.97 and mean relative error of less than $8.7 \%$. The results are significant for designing a highly efficient Venturi reactor having high temperature, high pressure, and three phases of gas, liquid, and solid.

\section{Notations}

$\begin{array}{ll}a_{0}, a_{1}, a_{2}, a_{3}, & \text { Undetermined constants } \\ \text { and } a_{4}: & \text { Characteristic diameter of pipe, } \mathrm{m} \\ d: & \text { Gas inlet diameter of the reactor, } \mathrm{m} \\ d_{1}: & \text { Throat diameter of the reactor, } \mathrm{m} \\ d_{2}: & \text { Diameter of the reactor, } \mathrm{m} \\ d_{5}: & \text { Modified Froud number } \\ \mathrm{Fr}^{\prime}: & \text { Acceleration due to gravity, } \mathrm{m} / \mathrm{s}^{2} \\ g: & \text { Altitude difference between the two } \\ h: & \text { measuring sections of a fluidized bed, } \mathrm{m}\end{array}$

$\begin{array}{ll}H: & \text { Height of liquid level in the reactor, } \mathrm{m} \\ R_{\mathrm{ls}}: & \text { Liquid-to-solid ratio } \\ R_{\mathrm{hd}}: & \text { Height-to-diameter ratio } \\ Q: & \text { Flow rate of fluid, } \mathrm{cm}^{3} / \mathrm{min} \\ u: & \text { Characteristic velocity, } \mathrm{m} / \mathrm{s} \\ U: & \text { Superficial velocity, } \mathrm{m} / \mathrm{s} \\ P: & \text { Pressure difference between the two } \\ \rho: & \text { measuring sections, } \mathrm{Pa} \\ \rho_{\text {mix }}: & \text { Density of fluid, } \mathrm{kg} / \mathrm{m}^{3} \\ \mu: & \text { Density of the mixture of gas and liquid, } \\ \varepsilon: & \text { kg/m }{ }^{3} \\ \pi: & \text { Giscosity of the fluid, Pa.s } \\ & \text { Gas holdup }\end{array}$

Subscripts

$p, m, l, s$, and The prototype, model, liquid, solid, and gas, $g$ : respectively.

\section{Data Availability}

The data used to support the findings of this study are available from the corresponding author upon request.

\section{Conflicts of Interest}

The authors declare that they have no conflicts of interest.

\section{Acknowledgments}

The authors are grateful to the National Natural Science Foundation of China and National 863 Plan of China for the financial support (Grant no. U1202274 and Grant no. 51204040).

\section{Supplementary Materials}

Figure S1: fitting coefficients a1, a2, a3, and a4 as obtained according to the slopes: (a) a1; (b) a2; (c, d) a3; (e) a4. Table S2: mean statistical variance of the results presented in Figure S1: the first and second columns are obtained from Figure S1 (a); first and third columns are obtained from Figure S1 (b); fourth and fifth columns are obtained from Figure S1 (c); sixth and seventh columns are obtained from Figure S1 (d); eighth column is obtained from Figure S1 (e). Table S3: relative error between the calculated and experimental results: The relative error: $\delta=\left(X_{i}-X_{c}\right) / X_{t} \times 100$, where $X_{i}$ is the experimental value and $X_{\mathrm{c}}$ is the calculated value. The mean relative error: $\sigma=\sqrt{\sum_{i=1}^{n} \delta^{2} / n}$, where $\sigma=8.7 \%$. (Supplementary Materials)

\section{References}

[1] W. Liu, J. Yang, and B. Xiao, "Review on treatment and utilization of bauxite residues in China," International Journal of Mineral Processing, vol. 93, no. 3-4, pp. 220-231, 2009.

[2] C. Klauber, M. Gräfe, and G. Power, "Bauxite residue issues: II. options for residue utilization," Hydrometallurgy, vol. 108, no. 1-2, pp. 11-32, 2011.

[3] W. Liu, S. Sun, L. Zhang, S. Jahanshahi, and J. Yang, "Experimental and simulative study on phase transformation in 
Bayer red mud soda-lime roasting system and recovery of $\mathrm{Al}$, $\mathrm{Na}$ and Fe," Minerals Engineering, vol. 39, pp. 213-218, 2012.

[4] S. Agatzini-Leonardou, P. Oustadakis, P. E. Tsakiridis, and C. Markopoulos, "Titanium leaching from red mud by diluted sulfuric acid at atmospheric pressure," Journal of Hazardous Materials, vol. 157, no. 2-3, pp. 579-586, 2008.

[5] S. Agrawal, V. Rayapudi, and N. Dhawan, "Extraction of iron values from red mud," Materials Today: Proceedings, vol. 5, no. 9, pp. 17064-17072, 2018.

[6] E. Mukiza, L. Zhang, X. Liu, and N. Zhang, "Utilization of red mud in road base and subgrade materials: a review," Resources, Conservation and Recycling, vol. 141, pp. 187-199, 2019.

[7] Y. Li, X. Min, Y. Ke, D. Liu, and C. Tang, "Preparation of red mud-based geopolymer materials from MSWI fly ash and red mud by mechanical activation," Waste Management, vol. 83, pp. 202-208, 2019.

[8] P. E. Tsakiridis, S. Agatzini-Leonardou, and P. Oustadakis, "Red mud addition in the raw meal for the production of Portland cement clinker," Journal of Hazardous Materials, vol. 116, no. 1-2, pp. 103-110, 2004.

[9] X. Xu, J. Song, Y. Li, J. Wu, X. Liu, and C. Zhang, "The microstructure and properties of ceramic tiles from solid wastes of Bayer red muds," Construction and Building Materials, vol. 212, pp. 266-274, 2019.

[10] M. A. Khairul, J. Zanganeh, and B. Moghtaderi, "The composition, recycling and utilisation of Bayer red mud," Resources, Conservation and Recycling, vol. 141, pp. 483-498, 2018.

[11] S. Vigneshwaran, M. Uthayakumar, and V. Arumugaprabu, "Development and sustainability of industrial waste-based red mud hybrid composites," Journal of Cleaner Production, vol. 230, pp. 862-868, 2019.

[12] R. Li, T. Zhang, Y. Liu, G. Lv, and L. Xie, "Calcificationcarbonation method for red mud processing," Journal of Hazardous Materials, vol. 316, pp. 94-101, 2016.

[13] G. Lu, T. Zhang, F. Guo et al., "Clean and efficient utilization of low-grade high-iron sedimentary bauxite via calcificationcarbonation method," Hydrometallurgy, vol. 187, pp. 195-202, 2019.

[14] R. Rakoczy and S. Masiuk, "Experimental study of bubble size distribution in a liquid column exposed to a rotating magnetic field," Chemical Engineering and Processing: Process Intensification, vol. 48, no. 7, pp. 1229-1240, 2009.

[15] A. Gordiychuk, M. Svanera, S. Benini, and P. Poesio, "Size distribution and Sauter mean diameter of micro bubbles for a Venturi type bubble generator," Experimental Thermal and Fluid Science, vol. 70, pp. 51-60, 2016.

[16] A. Mowla, T. Treeratanaphitak, H. M. Budman, N. M. Abukhdeir, and M. A. Ioannidis, "A meta-analysis of empirical correlations for average gas hold-up in three-phase fluidized beds," Powder Technology, vol. 301, pp. 590-595, 2016.

[17] M. Räsänen, T. Eerikäinen, and H. Ojamo, "Characterization and hydrodynamics of a novel helix airlift reactor," Chemical Engineering and Processing: Process Intensification, vol. 108, pp. 44-57, 2016.

[18] A. S. Mohamed, M. A. Herrada, J. M. López-Herrera, and A. M. Gañán-Calvo, "Isothermal dissolution of small rising bubbles in a low viscosity liquid," Chemical Engineering and Processing: Process Intensification, vol. 85, pp. 136-144, 2014.

[19] S. Maurer, M. Rüdisüli, S. L. Teske et al., "Transformation of local bubble rise velocity measurements to global results: shown by a Monte Carlo simulation of a fluidized bed,"
International Journal of Multiphase Flow, vol. 70, pp. 89-95, 2015.

[20] S. C. Saxena and N. S. Rao, "Estimation of gas holdup in a slurry bubble column with internals: nitrogen-therminolmagnetite system," Powder Technology, vol. 75, no. 2, pp. 153-158, 1993.

[21] N. P. Franka and T. J. Heindel, "Local time-averaged gas holdup in a fluidized bed with side air injection using X-ray computed tomography," Powder Technology, vol. 193, no. 1, pp. 69-78, 2009.

[22] K. Raghunathan, S. Kumar, and L.-S. Fan, "Pressure distribution and vortical structure in the wake behind gas bubbles in liquid and liquid-solid systems," International Journal of Multiphase Flow, vol. 18, no. 1, pp. 41-50, 1992.

[23] R. Li, T. A. Zhang, Y. Liu, J. Zhou, R. Zou, and S. Kuang, "Characteristics of red mud slurry flow in carbonation reactor," Powder Technology, vol. 311, pp. 66-76, 2017.

[24] Y. H. Tan, A. A. Rafiei, A. Elmahdy, and J. A. Finch, "Bubble size, gas holdup and bubble velocity profile of some alcohols and commercial frothers," International Journal of Mineral Processing, vol. 119, pp. 1-5, 2013.

[25] W. M. Verde, J. L. Biazussi, N. A. Sassim, and A. C. Bannwart, "Experimental study of gas-liquid two-phase flow patterns within centrifugal pumps impellers," Experimental Thermal and Fluid Science, vol. 85, pp. 37-51, 2017.

[26] P. Tyagi and V. V. Buwa, "Experimental characterization of dense gas-liquid flow in a bubble column using voidage probes," Chemical Engineering Journal, vol. 308, pp. 912-928, 2017.

[27] G. Besagni and F. Inzoli, "Comprehensive experimental investigation of counter-current bubble column hydrodynamics: holdup, flow regime transition, bubble size distributions and local flow properties," Chemical Engineering Science, vol. 146, pp. 259-290, 2016.

[28] K. H. K. Chung, M. J. H. Simmons, and M. Barigou, "Local gas and liquid phase velocity measurement in a miniature stirred vessel using PIV combined with a new image processing algorithm," Experimental Thermal and Fluid Science, vol. 33, no. 4, pp. 743-753, 2009.

[29] J. Sossa-Echeverria and F. Taghipour, "Computational simulation of mixing flow of shear thinning non-Newtonian fluids with various impellers in a stirred tank," Chemical Engineering and Processing: Process Intensification, vol. 93, pp. 66-78, 2015.

[30] A. Kazemzadeh, F. Ein-Mozaffari, A. Lohi, and L. Pakzad, "Intensification of mixing of shear-thinning fluids possessing yield stress with the coaxial mixers composed of two different central impellers and an anchor," Chemical Engineering and Processing: Process Intensification, vol. 111, pp. 101-114, 2017.

[31] G. P. Assima, A. Hamitouche, M. Schubert, and F. Larachi, "Liquid drainage in inclined packed beds-accelerating liquid draining time via column tilt," Chemical Engineering and Processing: Process Intensification, vol. 95, pp. 249-255, 2015.

[32] N. Yang, Z. Wu, J. Chen, Y. Wang, and J. Li, "Multi-scale analysis of gas-liquid interaction and CFD simulation of gasliquid flow in bubble columns," Chemical Engineering Science, vol. 66, no. 14, pp. 3212-3222, 2011.

[33] R. Zhou, N. Yang, and J. Li, "CFD simulation of gas-liquidsolid flow in slurry bubble columns with EMMS drag model," Powder Technology, vol. 314, pp. 466-479, 2017.

[34] R. Li, S. Kuang, T. Zhang, Y. Liu, and A. Yu, "Numerical investigation of gas-liquid flow in a newly developed carbonation reactor," Industrial \& Engineering Chemistry Research, vol. 57, no. 1, pp. 380-391, 2018. 
[35] A. A. Sonin, The Physical Basis of Dimensional Analysis, pp. 1-57, Dep. Mech. Eng. MIT, Cambridge, MA, USA, 2001.

[36] D. Wang, Y. Liu, Z. Zhang, P. Shao, and T. A. Zhang, "Dimensional analysis of average diameter of bubbles for bottom blown oxygen copper furnace," Mathematical Problems in Engineering, vol. 2016, Article ID 4170371, 8 pages, 2016.

[37] G. García-Ros, I. Alhama, M. Cánovas, and F. Alhama, "Derivation of universal curves for nonlinear soil consolidation with potential constitutive dependences," Mathematical Problems in Engineering, vol. 2018, Article ID 5837592, 15 pages, 2018.

[38] C. Boyadjiev, Theoretical Chemical Engineering, Modeling and Simulation, Springer-Verlag, Berlin, Germany, 2010.

[39] L.-S. Fan, F. Bavarian, R. L. Gorowara, B. E. Kreischer, R. D. Buttke, and L. B. Peck, "Hydrodynamics of gas-liquidsolid fluidization under high gas hold-up conditions," Powder Technology, vol. 53, no. 3, pp. 285-293, 1987.

[40] Y. Liu, M. Sano, T. Zhang, Q. Wang, and J. He, "Intensification of bubble disintegration and dispersion by mechanical stirring in gas injection refining," ISIJ International, vol. 49, no. 1, pp. 17-23, 2009.

[41] W. Mach, "Suspendierung fester Körper im turbulenten Gas/ Flüssigkeitsstrom," Chemie Ingenieur Technik, vol. 42, no. 5, pp. 311-316, 1970. 